\title{
Time requirement for capacitation of boar spermatozoa assessed by their ability to penetrate the zona-free hamster egg
}

\author{
H. Imai, K. Niwa and A. Iritani \\ Department of Animal Science, College of Agriculture, Kyoto University, Kyoto 606, \\ Japan
}

\begin{abstract}
Summary. Boar spermatozoa were preincubated for various times in the isolated uterus and oviduct from a maturing gilt and used to inseminate zona-free hamster eggs. The proportions of eggs penetrated and activated were increased, and the interval between insemination and sperm penetration was shortened when the spermatozoa were preincubated for $4-5.5 \mathrm{~h}$ instead of $2-3.5 \mathrm{~h}$. Overall penetration rates were higher and sperm penetration occurred about $1 \mathrm{~h}$ earlier when the eggs were inseminated with spermatozoa preincubated in the uterus than in the oviduct. It is concluded that the change in ability of boar spermatozoa to penetrate zona-free hamster eggs is due to capacitation which requires $4-4.5 \mathrm{~h}$ and $5-5.5 \mathrm{~h}$ of preincubation in the isolated uterus and oviduct, respectively.
\end{abstract}

\section{Introduction}

From studies on the penetration of zona-free hamster eggs by spermatozoa of the guinea-pig (Yanagimachi, 1972), mouse (Hanada \& Chang, 1972), rat (Hanada \& Chang, 1976) and man (Yanagimachi, Yanagimachi \& Rogers, 1976), it has been postulated that the incorporation of zona-free hamster eggs with foreign spermatozoa may be the result of sperm capacitation. In a previous study we observed that boar spermatozoa preincubated in the pig reproductive tract for several hours could penetrate zona-free hamster eggs (Imai, Niwa \& Iritani, 1977) and pig follicular oocytes matured in vitro (Iritani, Niwa \& Imai, 1978). These results indicate that the changes occurring in boar spermatozoa during preincubation in the isolated pig reproductive tract may be concomitant with sperm capacitation. Since there is little quantitative analysis of the fertilizing ability of boar spermatozoa, this paper reports a series of experiments with zonafree hamster eggs on the time requirement for capacitation of boar spermatozoa.

\section{Materials and Methods}

The medium used for manipulation of gametes was a modified Krebs-Ringer bicarbonate (KRB) solution, exactly as used in our previous study (Imai et al., 1977). Whole semen collected from a fertile Landrace or Hampshire boar was filtered through double gauze for removal of gel particles. Spermatozoa were washed twice by centrifugation for $10 \mathrm{~min}$ at $500 \mathrm{~g}$ and resuspended in $2-4 \mathrm{ml}$ of the medium to give a concentration of $2-10 \times 10^{8}$ spermatozoa $/ \mathrm{ml}$. About $0.1 \mathrm{ml}$ of the sperm suspension was diluted again in $2 \mathrm{ml}$ medium and preincubated at $37^{\circ} \mathrm{C}$ for $4-5 \mathrm{~h}$ in a $\mathrm{CO}_{2}$ incubator $\left(5 \% \mathrm{CO}_{2}\right.$ in air). Each of another two portions of the sperm suspension was introduced into a uterine horn $(0.2-0.3 \mathrm{ml})$ and/or oviduct $(0.01-0.03 \mathrm{ml})$ that had been removed from gilts immediately after slaughter. Gilts weighing about $80-100 \mathrm{~kg}$ and 
considered to be prepubertal were used because zona-free hamster eggs are more easily penetrated by boar spermatozoa preincubated in the reproductive tracts of maturing gilts than in those of oestrous sows (Imai et al., 1977). After the introduction of spermatozoa the ovarian end of the oviduct and the cervical end of the uterus were ligated and the reproductive tract was kept in $0.9 \%(\mathrm{w} / \mathrm{v}) \mathrm{NaCl}$ solution for $2,3-3.5,4-4.5$ or $5-5.5 \mathrm{~h}$ at $35-38^{\circ} \mathrm{C}$. After incubation the spermatozoa were recovered by flushing the oviducts and uteri with modified KRB solution. To remove blood cells and epithelial cell debris, flushings were gently centrifuged at $50 \mathrm{~g}$ for $5 \mathrm{~min}$ and the supernatant containing the spermatozoa was centrifuged again at $500 \mathrm{~g}$ for $10 \mathrm{~min}$. The sediment was resuspended in a small amount of the KRB medium. Some $(10-30 \mu l)$ of the sperm suspensions from the tract flushings and from the sample preincubated in a KRB solution were introduced into each plastic culture dish $(35 \times 11 \mathrm{~mm})$ containing zona-free hamster eggs. The final concentration of spermatozoa at insemination was $0.2-3.7 \times 10^{6}$ cells $/ \mathrm{ml}$.

Mature female golden hamsters were induced to superovulate by an i.p. injection of 25 i.u. PMSG 48-52 $\mathrm{h}$ before an i.p. injection of 25 i.u. hCG and killed 14-16 h after the hCG injection. The eggs in cumulus clots were recovered from the ampullary portion of the oviducts and treated for $1-15 \mathrm{~min}$ in medium containing $0.1 \%$ bovine testicular hyaluronidase (Sigma Chemical Co.). The eggs were then treated with $0.1 \%$ bovine pancreatic trypsin (BoehringerMannheim Co.) for 2-3 min to dissolve the zona pellucida. The zona-free eggs were washed twice with the KRB medium containing bovine serum albumin and introduced into $0.4 \mathrm{ml} \mathrm{KRB}$ medium covered with paraffin oil.

The eggs were mounted in toto, fixed, stained with lacmoid (Chang, 1952) 1-7 h after insemination with boar spermatozoa and examined for the evidence of sperm penetration under a phase-contrast microscope. The eggs which had an enlarged sperm head(s) or male pronucleus(ei) with the corresponding sperm tail(s) in the vitellus were considered to be penetrated. The number of activated eggs which had resumed the second maturation division at various stages after sperm penetration was also recorded.

\section{Results}

When zona-free hamster eggs were inseminated with boar spermatozoa preincubated in a modified KRB solution for 4-5 h, spermatozoa quickly attached to the surface of the vitelline membrane, but none of 403 eggs examined 1-7 h after insemination was penetrated.

As shown in Table 1, when boar spermatozoa were preincubated in the uterus or oviduct from a maturing gilt, the interval between insemination and sperm penetration into the zona-free hamster eggs was progressively reduced with increasing duration of preincubation. Overall penetration rates were greatly reduced when boar spermatozoa were preincubated in the uterus and oviduct for less than $4 \mathrm{~h}$. Overall penetration rates were also less when the eggs were inseminated with spermatozoa preincubated in the oviduct than with those from the uterus. Sperm penetration occurred about $1 \mathrm{~h}$ earlier when the eggs were inseminated with spermatozoa preincubated in the uterus than in the oviduct.

Two kinds of morphological changes in the sperm head were observed during enlargement after penetration; the first was the 'twisted' or 'waisted' appearance as reported by Hunter \& Dziuk (1968) and Hunter (1976), and the second was general enlargement. Most of the enlarged sperm heads with a 'waisted' appearance, but not those generally enlarged, were transformed into a pronucleus. When the eggs were inseminated with spermatozoa preincubated for 4-4.5 h in the uterus, transformation of the enlarged sperm head into the male pronucleus was observed in a high proportion of eggs penetrated and the proportions increased as the time after insemination progressed. Penetrated eggs with a male pronucleus were fewer when spermatozoa were preincubated in the oviduct than in the uterus and when preincubated for $2-3.5 \mathrm{~h}$ than for 4-4.5 h. The number of eggs activated to early anaphase of the second meiotic division or extrusion of the second polar body was higher in the eggs penetrated with spermatozoa preincubated in the uterus or oviduct for $4-4.5 \mathrm{~h}$ than for $2-3.5 \mathrm{~h}$. 
Table 1. Penetration of zona-free hamster eggs in vitro by boar spermatozoa preincubated in the reproductive tract isolated from a maturing gilt

\begin{tabular}{|c|c|c|c|c|c|}
\hline \multirow[b]{3}{*}{$\begin{array}{c}\text { Duration } \\
\text { of } \\
\text { preincubation } \\
\text { (h) }\end{array}$} & \multirow[b]{3}{*}{$\begin{array}{l}\text { Time of } \\
\text { examination } \\
\text { (h after } \\
\text { insem.) }\end{array}$} & \multicolumn{4}{|c|}{ Condition of sperm preincubation } \\
\hline & & \multicolumn{2}{|c|}{ Uterus } & \multicolumn{2}{|c|}{ Oviduct } \\
\hline & & $\begin{array}{c}\text { No. of eggs } \\
\text { penetrated*/ } \\
\text { no. examined } \\
(\%)\end{array}$ & $\begin{array}{l}\text { No. of eggs } \\
\text { activated/ } \\
\text { no. pentrated } \\
(\%)\end{array}$ & $\begin{array}{c}\text { No. of eggs } \\
\text { pentrated*/ } \\
\text { no. examined } \\
(\%)\end{array}$ & $\begin{array}{c}\text { No. of eggs } \\
\text { activated/ } \\
\text { no. penetrated } \\
(\%)\end{array}$ \\
\hline \multirow[t]{3}{*}{2} & 4 & $0+0 / 47(0)$ & - & $1+0 / 46(2)$ & $0 / 1(0)$ \\
\hline & 5 & $1+0 / 46(2)$ & $0 / 1(0)$ & $1+0 / 43(2)$ & $0 / 1(0)$ \\
\hline & 7 & $2+0 / 45(4)$ & $0 / 2(0)$ & $4+0 / 36(11)$ & $1 / 4(25)$ \\
\hline \multirow[t]{5}{*}{$3-3 \cdot 5$} & 2 & $0+0 / 41(0)$ & - & $0+0 / 48(0)$ & - \\
\hline & 3 & $0+0 / 45(0)$ & - & $0+0 / 44(0)$ & - \\
\hline & 4 & $6+0 / 72(8)$ & $0 / 6(0)$ & $7+1 / 77(10)$ & $1 / 8(12)$ \\
\hline & 5 & $14+1 / 64(23)$ & $1 / 15(7)$ & $6+0 / 43(14)$ & $0 / 6(0)$ \\
\hline & 7 & $11+1 / 33(36)$ & $1 / 12(8)$ & $7+0 / 38(18)$ & $0 / 7(0)$ \\
\hline \multirow[t]{6}{*}{$4-4 \cdot 5$} & 1 & $1+0 / 55(2)$ & $1 / 1(100)$ & $0+0 / 56(0)$ & - \\
\hline & 2 & $29+0 / 42(69)$ & $29 / 29(100)$ & $1+0 / 69(1)$ & $1 / 1(100)$ \\
\hline & 3 & $40+3 / 45(96)$ & $35 / 43(81)$ & $0+0 / 50(0)$ & - \\
\hline & 4 & $19+48 / 78(86)$ & $59 / 67(88)$ & $31+8 / 70(56)$ & $20 / 39(51)$ \\
\hline & 5 & $14+53 / 72(93)$ & $62 / 67(93)$ & $20+14 / 71(49)$ & $21 / 34(62)$ \\
\hline & 7 & $10+45 / 62(85)$ & $46 / 55(84)$ & $18+7 / 59(42)$ & $12 / 25(48)$ \\
\hline \multirow[t]{3}{*}{$5-5 \cdot 5$} & 1 & $21+0 / 46(46)$ & $20 / 21(95)$ & $3+0 / 35(9)$ & $3 / 3(100)$ \\
\hline & 2 & $37+5 / 42(100)$ & $42 / 42(100)$ & $23+0 / 52(44)$ & $18 / 23(78)$ \\
\hline & 3 & $0+36 / 36(100)$ & $36 / 36(100)$ & $29+4 / 54(61)$ & $23 / 33(70)$ \\
\hline
\end{tabular}

* The first figure denotes the number of eggs with an enlarged sperm head and the second denotes the number of eggs with a male pronucleus.

The motility of the spermatozoa was extremely poor when recovered from the reproductive tracts, but always improved after washing. However, it was inferior to that of spermatozoa preincubated in a KRB solution and was always better for spermatozoa preincubated in the uterus than in the oviduct. The motility of spermatozoa during incubation with zona-free hamster eggs was well maintained when preincubated in the uterus, but it was weakened with increasing time of incubation with eggs when they were preincubated in the modified KRB solution or in the oviduct.

To determine whether zona-free hamster eggs penetrated with boar spermatozoa could cleave after a longer time of culture, eggs inseminated with spermatozoa preincubated in the uterus for $4.5 \mathrm{~h}$ were examined $24 \mathrm{~h}$ after insemination. None of $11 \mathrm{eggs}$ examined had cleaved but two or more pronuclei which had a large number of nucleoli were observed. However, there were no signs of the penetrating sperm tail or the second polar body in any of the eggs examined.

\section{Discussion}

In a previous study on penetration of zona-free hamster eggs in vitro by ejaculated boar spermatozoa, there were wide variations in the duration $(4-10 \mathrm{~h})$ of sperm preincubation in the pig reproductive tract and in the concentration $\left(0.01-11.1 \times 10^{6} / \mathrm{ml}\right)$ of spermatozoa used for insemination (Imai et al., 1977). From the results of the present study carried out with a more limited duration of preincubation time and sperm concentration $\left(0.2-3.7 \times 10^{6}\right.$ spermatozoa $/ \mathrm{ml}$ ) at insemination, it is quite clear that boar spermatozoa can acquire an ability to penetrate zona-free hamster eggs during preincubation in the reproductive tract isolated from a 
maturing gilt and that this change in ability is progressively completed with increasing duration of sperm preincubation up to $5-5 \cdot 5 \mathrm{~h}$. Since it is known that boar spermatozoa are capacitated while passing through the female tract in vivo (Hunter \& Hall, 1974a, b), and that they penetrate in vitro pig oocytes matured in culture when they are preincubated in the isolated female tract for 4.5-5 h (Iritani et al., 1978), it is concluded that the change of boar spermatozoa to penetrate zona-free hamster eggs must be concomitant with their capacitation. The results of this study also suggest that a modified KRB solution does not have the ability to induce capacitation of boar spermatozoa, although one zona-free hamster egg $(2 \%)$ was penetrated with boar spermatozoa preincubated in a modified KRB solution in the previous study (Imai et al., 1977).

It has been reported that a population of capacitated spermatozoa first becomes available in the oviduct of oestrous pigs within 2-3 h of semen deposition by mating or artificial insemination (Hunter \& Dziuk, 1968; Hunter, 1972). In the present study overall penetration rates were very low when zona-free hamster eggs were inseminated with boar spermatozoa preincubated for less than $4 \mathrm{~h}$ in the uterus and oviduct isolated from a maturing gilt. This discrepancy may be due to the difference of physiological conditions of the female tract in which the spermatozoa were deposited, especially since overall penetration rates were better and sperm penetration occurred about $1 \mathrm{~h}$ earlier when spermatozoa preincubated in the uterus were used. Furthermore, the deposition of too many spermatozoa $\left(2-30 \times 10^{6}\right)$ in the limited environment of the oviduct might have resulted in a lower ability to capacitate the spermatozoa preincubated there.

In the previous study the proportion of penetrated eggs with a male pronucleus was very low when zona-free hamster eggs were inseminated with boar spermatozoa preincubated in the uterus $(5 / 19=26 \%)$ and oviduct $(0 / 15=0 \%)$ of a maturing gilt (Imai et al., 1977), and our present results, especially those with spermatozoa preincubated for $2-3.5 \mathrm{~h}$ in the uterus or oviduct, are similar, although increasing with time after insemination.

Some of this work was supported by a grant from Ford Foundation (No. 7400404).

\section{References}

Chang, M.C. (1952) Fertilizability of rabbit ova and the effects of temperature in vitro on their subsequent fertilization and activation in vivo. J. exp. Zool. 121, $351-382$.

Hanada, A. \& Chang, M.C. (1972) Penetration of zonafree eggs by spermatozoa of different species. Biol. Reprod. 6, 300-309.

Hanada, A. \& Chang, M.C. (1976) Penetration of hamster and rabbit zona-free eggs by rat and mouse spermatozoa with special reference to sperm capacitation. J. Reprod. Fert. 46, 239-241.

Hunter, R.H.F. (1972) Fertilization in the pig: sequence of nuclear and cytoplasmic events. J. Reprod. Fert. 29, 395-406.

Hunter, R.H.F. (1976) Sperm-egg interactions in the pig: monospermy, extensive polyspermy, and the formation of chromatin aggregates. J. Anat. 122, 4359.

Hunter, R.H.F. \& Dziuk, P.J. (1968) Sperm penetration of pig eggs in relation to the timing of ovulation and insemination. J. Reprod. Fert. 15, 199-208.
Hunter, R.H.F. \& Hall, J.P. (1974a) Capacitation of boar spermatozoa: synergism between uterine and tubal environments. J. exp. Zool. 188, 203-214.

Hunter, R.H.F. \& Hall, J.P. (1974b) Capacitation of boar spermatozoa: the influence of post-coital separation of the uterus and Fallopian tubes. Anat. Rec. 180, 597-604.

Imai, H., Niwa, K. \& Iritani, A. (1977) Penetration in vitro of zona-free hamster eggs by ejaculated boar spermatozoa. J. Reprod. Fert. 51, 495-497.

Iritani, A., Niwa, K. \& Imai, H. (1978) Sperm penetration in vitro of pig follicular oocytes matured in culture. J. Reprod. Fert. 54, 379-383.

Yanagimachi, R. (1972) Penetration of guinea-pig spermatozoa into hamster eggs in vitro. J. Reprod. Fert. 28, 477-480.

Yanagimachi, R., Yanagimachi, H. \& Rogers, B.J. (1976) The use of zona-free animal ova as a testsystem for the assessment of the fertilizing capacity of human spermatozoa. Biol. Reprod. 15, 471476.

Received 22 September 1978 